University of Nebraska - Lincoln

DigitalCommons@University of Nebraska - Lincoln

$11-1-2007$

\title{
Perinatal $\mathrm{pH}$ and neuropsychological outcomes at age 3 years in children born preterm: An exploratory study
}

\author{
Kimberly A. Espy \\ University of Nebraska-Lincoln, kespy2@unl.edu \\ Theresa E. Senn \\ Syracuse University \\ David A. Charak \\ Learning Point Associates, Naperville, Illinois \\ Jill Tyler \\ Southern Illinois University \\ Sandra A. Wiebe \\ University of Nebraska-Lincoln, sandra.wiebe@ualberta.ca
}

Follow this and additional works at: https://digitalcommons.unl.edu/dcnlfacpub

Part of the Neurosciences Commons

Espy, Kimberly A.; Senn, Theresa E.; Charak, David A.; Tyler, Jill; and Wiebe, Sandra A., "Perinatal pH and neuropsychological outcomes at age 3 years in children born preterm: An exploratory study" (2007). Developmental Cognitive Neuroscience Laboratory - Faculty and Staff Publications. 1.

https://digitalcommons.unl.edu/dcnlfacpub/1

This Article is brought to you for free and open access by the Developmental Cognitive Neuroscience Laboratory at DigitalCommons@University of Nebraska - Lincoln. It has been accepted for inclusion in Developmental Cognitive Neuroscience Laboratory - Faculty and Staff Publications by an authorized administrator of DigitalCommons@University of Nebraska - Lincoln. 


\title{
Perinatal $\mathrm{pH}$ and Neuropsychological Outcomes at Age 3 Years in Children Born Preterm: An Exploratory Study
}

\author{
Kimberly Andrews Espy \\ Office of Research and Department of Psychology \\ University of Nebraska-Lincoln \\ Theresa E. Senn \\ Department of Psychology \\ Syracuse University \\ David A. Charak \\ Learning Point Associates \\ Naperville, Illinois \\ Jill Tyler \\ School of Medicine \\ Southern Illinois University \\ Sandra A. Wiebe \\ Office of Research and Department of Psychology \\ University of Nebraska-Lincoln
}

\begin{abstract}
The impact of extreme prematurity and related hypoxic-ischemic events on brain development recently has begun to be characterized with modern neuroimaging methods, although comparatively less is known about the neuropathology in those born at heavier birth weights. Even subclinical levels of perinatal hypoxia-ischemia, as indexed by perinatal blood $\mathrm{pH}$, are related to intelligence in school-aged children born preterm. Given the impact of hypoxia-ischemia on white matter and the emerging evidence of specific executive and mathematic deficits in children born preterm, the
\end{abstract}

Correspondence should be addressed to Kimberly Andrews Espy, Associate Vice Chancellor for Research, 303 Canfield Administration Building, University of Nebraska-Lincoln, Lincoln, NE 68588-0433. E-mail: kespy2@unl.edu 
impact of perinatal hypoxia-ischemia on these outcomes was explored in children at relatively low-risk for sequelae. In a sample of 22 preschool children born preterm, arterial blood $\mathrm{pH}$ values obtained within the first $3 \mathrm{~h}$ of life were abstracted from review of hospital medical charts, and then related to specific cognitive task performance at age 3 years. Mean initial $\mathrm{pH}$ was in the normal to subclinical range. Initial $\mathrm{pH}$ appears to be a strong predictor of specific mathematics and controlled attention abilities, and is not limited to general verbal ability alone. However, initial $\mathrm{pH}$ was not related to performance on measures of motor impulsivity or working memory. As a screening index of subtle hypoxia-ischemia, these findings suggest that perinatal arterial blood $\mathrm{pH}$ warrants further study as a potential marker of subtle hypoxicischemic injury that likely affects cognitive outcome throughout childhood in those at risk due to preterm birth.

A remarkably consistent picture of the outcomes associated with preterm birth is emerging. On average, children born preterm perform lower on intelligence tests than their fullterm peers by 5 to 11 points, with a "dose-response" effect noted as a function of birth weight, even after adjusting for sociodemographic influences. As these observed differences on intelligence tests can be considered to represent the amalgam of skill discrepancies in more discrete cognitive operations (Aylward, 2005), finer-grained examinations of specific neuropsychological abilities reveal deficits in motor coordination and tone (e.g., Breslau, Chilcoat, \& Johnson, 2000), fine motor-visuomotor skills (e.g., Dewey, Crawford, \& Creighton, 1999; Whitfield, Eckstein-Grunau, \& Holstik, 1997), and attention and executive functions, particularly working memory (e.g., Anderson \& Doyle, 2004; Espy et al., 2002; Luciana, Lindeke, Georgieff, Mills, \& Nelson, 1999; Taylor, Hack, \& Klein, 1998). In preschoolers, language delays are common. By school age, however, vocabulary and receptive language are not as compromised as are non-verbal skills (e.g., Frisk \& Whyte, 1994; Ment, Vohr, Allan, \& Peterson, 2003;Taylor, Burant, \& Holding, 2002), although some investigators have noted deficiencies on more complex verbal tasks, such as syntax. Not surprisingly, these cognitive skill deficits contribute to the routinely observed academic difficulties in children born preterm (e.g., Taylor, Hack, Klein, \& Schatschneider, 1995). For example, 1/2 to 3/4 of those born preterm require special assistance at school (Saigal, den Ouden, \& Wolke, 2003) and the risk for learning disabilities are substantially higher in children born preterm relative to full term peers (Saigal, Hoult, \& Streinder, 2000; Taylor \& Alden, 1997), with particular vulnerability in mathematics (e.g., Espy et al., 2004; Taylor, Klein, Minich, \& Hack, 2000).

Concomittantly, the application of both volumetric and functional neuroimaging technologies has resulted in significant advances in understanding the "brain basis" of the impact of preterm birth on outcome (e.g., Huppi, Warfield, \& Kikinis, 1998, Peterson et al., 2000). In these studies, differences in cortical volumes in the hippocampus and other grey matter (Isaacs et al., 2000; Marin-Padilla, 1999; Pe- 
terson, Anderson, \& Ehrenkranz, 2003), in function and morphometry of prefrontal systems including the basal ganglia (Allin, Henderson, \& Suckling, 2004; Peterson et al., 2000), and importantly extensive damage to white matter (Inder, Huppi, \& Warfield, 1999; Volpe, 1995) have been observed. These results with diverse neuroimaging methods reveal remarkable consistency with what had been hypothesized to be vulnerable on the basis of the neuropathology of preterm birth and associated medical complications, and by careful consideration of the pattern of neuropsychological deficits often observed in children born preterm. Although these changes in brain structure and function can be detected with modern neuroimaging methods, the specific neuropathogenesis of the observed lesions is less clear. Outcome differences are undoubtedly due, in part, to disturbance of brain structure and function, but it is difficult to tease apart the potentially disruptive influences of preterm birth on the brain per se, from those due directly to CNS injury, such as intraventricular hemorrhage and hypoxic-ischemic injury. The CNS develops rapidly during the second and third trimesters, particularly in progressive differentiation and myelination, which are vulnerable to disruption by preterm birth (Dammann \& Leviton, 1999). Although the deleterious impact of intraventricular hemorrhage on outcome has been identified for some time, only more recently has the impact of even subtle hypoxia-ischemia insults been recognized as important. Hypoxia sets off an excitotoxic cascade of massive glutamate release, leading to a rapid influx of calcium, prolonged depolarization, and excitation that exhausts cell energy supplies, leading to cell death. This cascade causes local cell death in the form of necrosis, but also death of cells at more distant sites, and later in time, through apoptosis. This cascade then is followed by a second course of injury caused by reperfusion to the injured site, with the influx of free radicals associated with further oxidative injury. In preterm infants, hypoxia-ischemia is associated with cell death deeper in the brain, with greater vulnerability of injury to the white matter surrounding the lateral ventricles (Volpe, 1995).

Most of the outcome studies have focused on those children born at extremely low birth weights because of the greater threat to mortality and the greater likelihood of neurobiologic risks and insults that affect morbidity. It is less clear what determines differences in outcome in those children born preterm who are of higher birth weights. Although these children also are at elevated risk for learning and attention disorders relative to those born full term, evidence of gross pathology on neonatal ultrasound often is absent or inconsistent (e.g., Aziz et al., 1995; Isaacs et al., 2000), and not all of these children demonstrate even more minor lesions such as gliosis on the more sensitive MRIs conducted later in life. Hypoxiaischemia likely is not categorically distributed - that is, not reflected in presence or absence, but rather, distributed along a continuum. Therefore, heavier infants might experience varying degrees of hypoxic-ischemic injury that might not result in grossly abnormal findings on modern neuroimaging tools and yet may account for substantive variation in outcome. One complicating feature in detecting hy- 
poxic-ischemic damage is that the standard of care does not include the routine use of the more sensitive neuroimaging techniques like MRI in extremely low birth weight infants, let alone in infants born at heavier weights who are at substantially lower risk for adverse sequelae.

The purpose of this exploratory study was to investigate the role of perinatal hypoxia-ischemia on later outcome in low-risk children born preterm. One index of hypoxia-ischemia that is used routinely in the clinical context is the Apgar score, measured at 1 and 5 min after birth. The Apgar score, although sensitive to hypoxic-ischemic risk in fullterm infants, is a less specific indicator in preterm infants because of the confounding of biologic immaturity. The Apgar score consists of ratings on heart rate, respiration, muscle tone, color, and reflexes. Many preterm infants, regardless of their perinatal course, are unable to achieve the maximal ratings in each category due to physiological immaturity, rather than compromise in organ function per se.

Another clinically available measure of hypoxia-ischemia that has not been utilized as routinely in cognitive outcome studies is $\mathrm{pH}$ measured from neonatal arterial blood. $\mathrm{pH}$ is an index of the concentration of $\mathrm{H}+$ ions in blood. It is considered the "gold standard," where the lower the $\mathrm{pH}$, the more acidotic is the infant's blood chemistry. $\mathrm{pH}$ is on a negative logarithmic scale, where a $\mathrm{pH}$ of 7.2 contains $40 \%$ more $\mathrm{H}+$ ions than a $\mathrm{pH}$ of 7.35 . In first $24 \mathrm{~h}$ of life, acceptable arterial $\mathrm{pH}$ is 7.35 to 7.44, with 7.1 to 7.3 considered to be moderately acidotic (Korones, 1979). $\mathrm{pH}$ is considered a marker of hypoxic-ischemic injury because during hypoxia, anaerobic metabolism is prominent, leading to the build-up of lactate and other acids that cannot be effectively neutralized (Stevenson \& Sunshine, 1997).

There is recent evidence that $\mathrm{pH}$ might serve as a marker of subtle brain compromise, even in those without evidence of structural changes on clinical neuroimaging methods. Stevens, Raz, and Sander (1999) demonstrated that subclinical (moderate) levels of acidosis, between 7.1 and 7.3, were related to both overall and verbal intelligence scores in 4- to 7-year-old preterm and fullterm children. Interestingly, in a mixed sample of 4- to 6-year-old very low risk preterm and fullterm children (sample mean birthweight of $2258 \mathrm{~g}$ and birth gestational age of 33.5 weeks), $\mathrm{pH}$ was not related to non-verbal intelligence. These findings are surprising, given that non-verbal skill deficits are a commonly observed sequalae in those born preterm. In a subsequent study (Hopkins-Golightly, Raz, \& Sander, 2003), $\mathrm{pH}$ was related to both verbal and non-verbal abilities in a sample composed only of children born preterm. If performance on tests of intelligence is considered to represent an amalgam of neuropsychological abilities, the findings in the Raz and colleagues studies suggest that $\mathrm{pH}$ might be related to more specific outcomes in children born preterm. The purpose of the present study was to explore whether $\mathrm{pH}$ at birth predicts discrete neuropsychological abilities. To investigate this possibility, measures of general vocabulary were included for replication, in addition to tasks designed to assess working memory, impulsivity, sustained attention, and 
mathematics, in order to investigate specific outcomes that have been shown to be impaired in children born preterm. Finally, the utility of $\mathrm{pH}$ as a predictor of outcome was contrasted informally to the commonly used clinical indicators, Apgar scores measured at 1 and 5 min after birth.

\section{METHODS}

\section{Participants}

Twenty-two preschool children born preterm participated (12 females, 10 males; 17 children of White race/ethnicity and 5 of minority race/ethnicity). These preschoolers participated previously in a neonatal study designed to assess the impact of biological risk factors on the development of early attention skills during neonatal hospitalization (Eidem \& Espy, 2005; Espy, Senn, \& Cunningham, 2001). For that study, neonates admitted to the neonatal intensive care unit who were at low risk for severe sequelae (gestational age $\geq 28$ and $\leq 35$ weeks, birth weight $\geq 1250$ and $\leq 2500 \mathrm{~g}$, and not requiring surgery) were recruited prospectively shortly after delivery for study participation. They were administered a neonatal behavioral examination three times a week while hospitalized until discharge. At that time, their medical chart and that of their mother, was reviewed, and the information (including the arterial blood $\mathrm{pH}$ screening used in the present study) coded by study staff. Gestational age was determined systematically using the information provided on the infant and maternal medical chart and prenatal records, using the system of DiPietro and Allen (1991).

Later, a preliminary, three-year-old follow-up study was initiated to obtain longer-term outcome on available participants who (a) would be three years of age within the window of data collection, (b) could be contacted, and (c) agreed to participate. The purpose here was not to understand the incidence of low initial $\mathrm{pH}$ in a representative cohort of children born preterm, rather to begin to characterize the potential impact of low initial $\mathrm{pH}$ in low risk children born preterm. For their data to be included in this report, arterial blood $\mathrm{pH}$ had to be measured within the first 3 $\mathrm{h}$ of life, and the $\mathrm{pH}$ value had to fall within the normal to subclinical range, consistent with Raz and colleagues procedure (Hopkins-Golightly et al., 2003; Stevens et al., 1999). In this hospital, initial $\mathrm{pH}$ was charted as a screening index for low risk infants, without the other blood values (e.g., $\mathrm{PaCO} 2$ ) for most infants. Therefore, only initial $\mathrm{pH}$ was used as a predictor in this exploratory study. Infants with necrotizing enterocolitis, chronic lung disease, intraventricular hemorrhage or periventricular injury, sepsis, or seizure disorder during their hospital course were excluded from participation in order to sample only those at low risk for frank brain disturbance and adverse outcome.

The sample characteristics are provided in Table 1. At birth, the mean gestational age of the sample was 32.26 weeks $(S D=2.04)$, with an average birth weight 
TABLE 1

Sample Characteristics

\begin{tabular}{lccc}
\hline Variable & Mean & $S D$ & Range \\
\hline Child Age (years) & 3.01 & .4 & $12.50-3.67$ \\
autoMaternal Education (yrs) & 13.8 & 62.32 & $12-20$ \\
Maternal Age at Delivery (yrs) & 26.71 & 6.08 & $18-39$ \\
Birth Gestational Age (weeks) & 32.26 & 2.04 & $30.5-34.5$ \\
Birth Weight (g) & 1749 & 332 & $149-2475$ \\
Days of Hospitalization & 25.43 & 13.91 & $8-53$ \\
Days on Oxygen & 3.33 & 7.00 & $0-30$ \\
pH & 7.297 & 0.059 & $7.163-7.409$ \\
Apgar @ 1 min. & 6.68 & 1.59 & $1-9$ \\
Apgar @ 5 min. & 8.32 & .99 & $6-9$ \\
\hline
\end{tabular}

of $1749 \mathrm{~g}(S D=332)$. Sixteen of these infants were of low birth weight, and six were of very low birth weight. Although 18 out of 22 participants received some type of oxygen therapy after birth, as expected with such a low risk sample, the number of days that the neonate received oxygen therapy was low. Concomittantly, most babies were hospitalized for approximately 1 month. The Apgar scores at 1 and 5 min were consistent with expectations given the nature of the sample. Mean $\mathrm{pH}$ for the sample was 7.297, in the moderately acidotic range.

\section{Measures}

For the purposes of replication, the Picture Vocabulary subtest from the Woodcock-Johnson Psycho-Educational Battery-Revised (WJ-R; Woodcock, \& Johnson, 1989) was administered to assess general verbal skills (Sattler, 1992). In this vocabulary task, the child points to the picture that best represents the word provided by the examiner. One benefit of the WJ-R subtests is that the items are graded in difficulty, determined empirically through Rasch item analysis (W score). Therefore, the $\mathrm{W}$ score was used as the dependent variable.

Executive control was assessed by including tasks that demanded maintaining information across trials. In Six Boxes (Diamond, Prevor, Callender, \& Druin, 1997), an experimental task adapted from Diamond et al. modeled after tasks that have been used to study working memory in non-human animals (Levin \& Bowman, 1986) and adult humans (Petrides, 1995), there are two conditions: verbal and non-verbal. In both conditions, rewards (stickers) were hidden in each of six small boxes while the child watched. The child was instructed to find a reward each time the boxes were presented, with the array of boxes presented again to the child over a series of trials until all rewards were retrieved. Between trials, boxes were hidden behind a shield for a 10-sec delay. In the Non-spatial condition, differently 
shaped and colored boxes that are rearranged between trials are used to conceal the reward; therefore, the child had to use verbal information (shape/color) to find the reward. In the Spatial condition, six identical white, square boxes that remained in the same location were utilized, where the child had to recall the spatial location to correctly retrieve the reward. The number of trials to find all rewards was recorded, with separate average efficiency scores (number of unique boxes opened divided by number of trials administered) calculated for the Spatial and Non-spatial conditions, respectively.

Self control (Lee, Vaughn, \& Kopp, 1983) was administered to index impulsivity in light of a reward. In this task at the conclusion of testing, the child was presented with an attractively wrapped gift. The gift was placed on the table in front of the child, who was instructed not to touch the gift until the examiner had finished another task. The examiner then actively disengaged from the child by performing another activity (e.g., reviewing test sheets) while surreptitiously observing the child. The latency to touch the gift (with a maximum of $150 \mathrm{sec}$ ) was recorded.

Selective and sustained attention was assessed by Visual Attention (Korkman, Kirk, \& Kemp, 1998), one of the attention/executive function domain subtests of the NEPSY. Here, children were instructed to find items that matched the target stimuli among a page of targets and distractors. However, unlike the traditional NEPSY administration, all children completed only one trial, the random array of cats, using a stamper in order to reduce the motor proficiency demands. Total time required to complete the page was recorded, with 3 min maximum allowed. An efficiency score was calculated, using the difference between the number of targets and commission errors and then dividing the time to complete the page (e.g., Riccio, Reynolds, \& Lowe, 2001).

The WJ-R Applied Problems (Woodcock \& Johnson, 1989) subtest was selected as a measure of emergent mathematics abilities. Specific mathematic content on this subtest is mixed, including subitizing, ordinal counting, counting relevant object items among mixed object groups, and simple subtraction and addition calculations. Children were shown a picture that depicted the math problem read by the examiner, and then pointed to, or verbalized, the answer. The $\mathrm{W}$ score was used for the analyses.

\section{Procedure}

Children were administered the battery of tasks in a single session by a trained graduate student blind to the experimental hypotheses. Sessions were conducted individually in a quiet room, with the parent or guardian present in the back of the room completing study forms, to minimize any separation difficulties in these young children. To foster cooperation and interest, short breaks 
were used. Families received monetary and small trinket compensation for participation.

\section{RESULTS}

To address the study hypotheses, linear regression analysis was used to determine the relation of initial arterial blood $\mathrm{pH}$ on neuropsychological outcome at age 3 . Analyses were conducted using SAS. Because there was some variability in at what age children were evaluated, chronological age was controlled in all analyses. Furthermore, because the interest was in the contribution of $\mathrm{pH}$ to neuropsychological outcome independent of the degree of prematurity, birth gestational age also was controlled statistically. Sample performance on all tasks is provided in Table 2.

Results are presented in Table 3. Initial $\mathrm{pH}$ was related to performance on the WJ-R Picture Vocabulary subtest at age 3 years as hypothesized, $\beta=.43, t(2.12)$, $p<.04$. Children with lower $\mathrm{pH}$, that is whose arterial blood was more acidotic at birth, identified fewer words at age 3 years than preschool aged children with

TABLE 2

Sample Task Performance

\begin{tabular}{lccc}
\hline Task & Mean & \multicolumn{1}{c}{ SD } & Range \\
\hline Six Boxes-Non-spatial & 0.68 & 0.19 & $0.42-1.00$ \\
Six Boxes_Spatial & 0.64 & 0.21 & $0.33-1.00$ \\
Self-Control & 63.41 & 59.20 & $1-150$ \\
NEPSY Visual Attention-Cats & 0.025 & 0.11 & $-0.22-0.17$ \\
13 WJ-R Picture Vocabulary & 97.91 & 12.84 & $79-125$ \\
WJ-R Applied Problems W score & 93.00 & 15.37 & $65-125$ \\
\hline
\end{tabular}

TABLE 3

Relations (Standardized Beta Weights) Between Task Performance and Indicators of Hypoxia-Ischemia, After Adjusting for the Influence of Child Age and Gestational Age at Birth

\begin{tabular}{lccc}
\hline Task & $p H$ & Apgar @ 1 min & Apgar @ 5 min \\
\hline Six Boxes-Non-spatial & $-0.06(.24)$ & $-0.05(.27)$ & $-0.07(.28)$ \\
Six Boxes-Spatial & $-0.20(.21)$ & $-0.38(.23)$ & $-0.48^{*}(.22)$ \\
Self Control & $-0.20(.24)$ & $0.49^{\mathrm{t}}(.26)$ & $0.25(.29)$ \\
NEPSY Visual Attention-Cats & $0.49^{*}(.22)$ & $0.00(.28)$ & $0.14(.28)$ \\
WJ-R Picture Vocabulary & $0.43^{*}(.20)$ & $0.14(.25)$ & $0.14(.26)$ \\
WJ-R Applied Problems & $0.54^{*}(.20)$ & $0.29(.26)$ & $0.14(.27)$ \\
\hline
\end{tabular}

Standard errors provided in parentheses. ${ }^{*} p<.05 .{ }^{\mathrm{t}} p<.10$. 
higher initial $\mathrm{pH}$ values at birth. In addition, initial arterial $\mathrm{pH}$ at birth also was related to performance on the NEPSY Visual Attention, $\beta=.49, t(2.32), p<.05$, and the WJ-R Applied Problems subtests, $\beta=.54, t(2.69), p<.02$, at age 3 years. Preschool children born preterm with lower initial arterial $\mathrm{pH}$ at birth made more commission errors and identified fewer targets, and were able to solve fewer simple mathematics problems at age 3 years than those with higher initial arterial $\mathrm{pH}$ values at birth. The zero-order correlations between these outcomes at age 3 years and initial arterial $\mathrm{pH}$ at birth are depicted graphically in Figure 1. In contrast, initial arterial $\mathrm{pH}$ at birth was unrelated to performance at preschool age on either of the Six Boxes conditions or on Self Control (all $p$ 's $>$.34).

In contrast, Apgar scores taken at 1 and 5 min largely was unrelated to neuropsychological outcome at age 3 years in children born preterm. Apgar scores measured at $5 \mathrm{~min}$ post birth was related to performance on the Spatial condition of the Six Boxes task at age 3 years, $\beta=-.48, t(2.14), p<.05$. Surprisingly, preschool children with higher Apgar scores measured 5 min after birth searched less efficiently on this condition; that is, they required more trials to find the rewards. Apgar score assessed at $1 \mathrm{~min}$ after birth also was related marginally to performance on Self Control at age 3 years in children born preterm, $\beta=.49, t(1.87), p<$ .08 , where children with higher Apgar scores 1 min after birth were able to wait longer to obtain the reward at age 3 years, relative to those with lower Apgar scores at $1 \mathrm{~min}$ after birth. Apgar scores at 1 and $5 \mathrm{~min}$ were not related to performance on any of the other neuropsychological measures, all $p$ 's $>.10$.

\section{DISCUSSION}

The purpose of this preliminary study was to explore the relation between $\mathrm{pH}$ collected shortly after birth and cognitive outcome at age 3 years in children born preterm at low risk for adverse sequelae. As hypothesized, and similar to Raz and colleagues (Stevens et al., 1999; Hopkins-Golightly et al., 2003) in samples of school age children born preterm, $\mathrm{pH}$ was related to receptive vocabulary in preschool aged children at age 3 years. The consistency of these findings across albeit small samples of children born preterm, but who differ as a group in weights at birth, ages at evaluation, and in the type of verbal intellectual tasks administered, is notable. The consistency of this relation across study methods and sampling characteristics suggests that perinatal $\mathrm{pH}$ may be a robust marker of general cognitive outcome in low risk children born preterm. Also of note is the level of performance at which this relation was observed- $\mathrm{pH}$ was related to outcome where mean group was in the average range. The sensitivity within normal to subclinical ranges of $\mathrm{pH}$ to variations in the typically developing range of cognitive performance at 3 


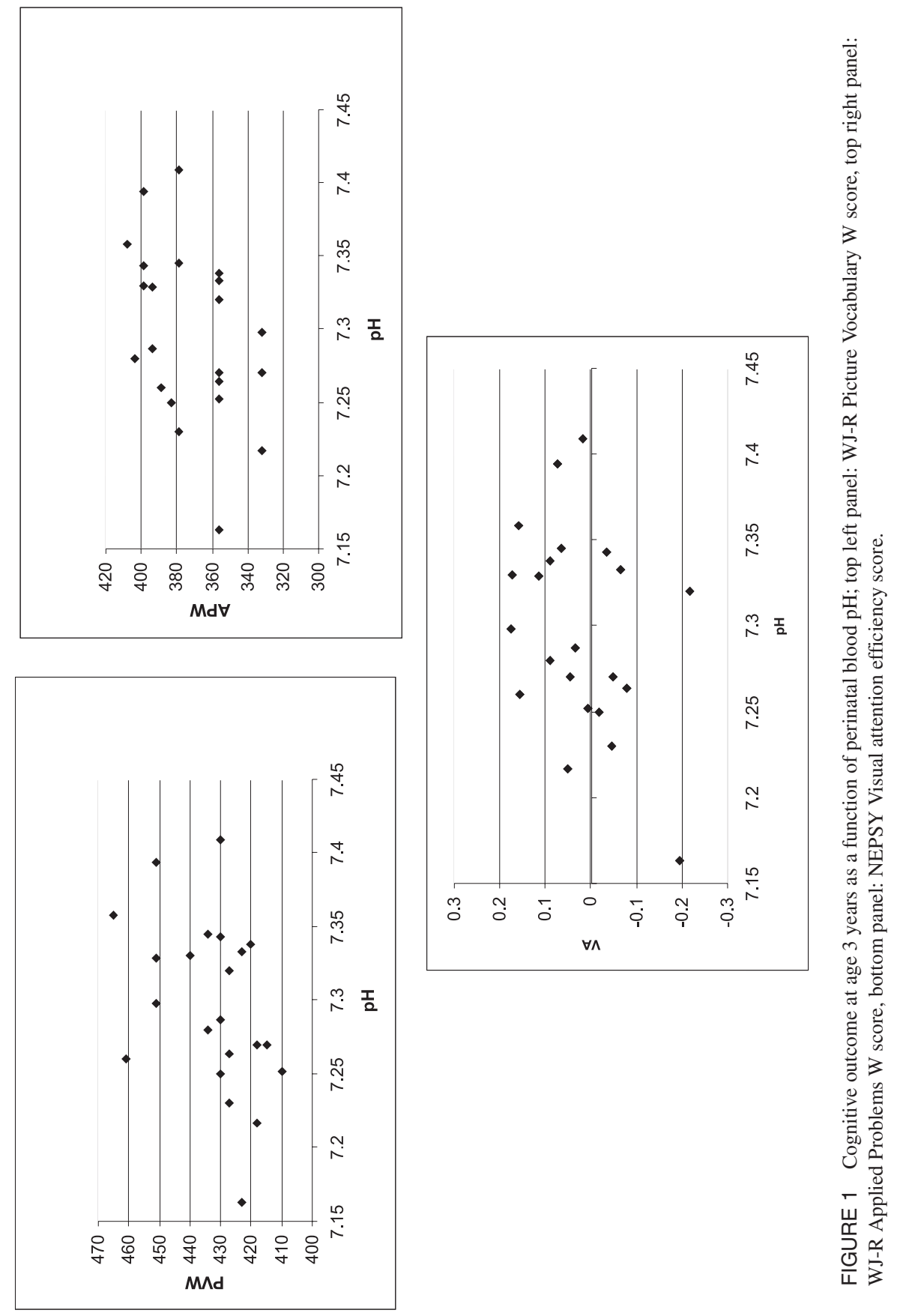


years after birth is substantive and merits further examination in larger scale, prospective studies.

These preliminary findings extend those of Raz and colleagues (Golightly et al., 2003; Stevens, Raz, \& Sander, 1999) into two additional domains of cognitioncontrolled attention and emergent mathematics. Deficits in mathematics are found commonly in children born preterm, even in lower risk samples as was observed here (e.g., Espy et al., 2004; Taylor et al., 1995; 2000). Furthermore, it is of note that $\mathrm{pH}$ is related to controlled attention (Taylor, Hack, \& Klein, 1998), as measured on the NEPSY Visual Attention subtest, but not to performance on a task meant to capture motor impulsivity in the context of reward. Clinically, children born preterm more commonly show primary deficits with control and maintenance of attention (Lou, 1996; Szatmari, Saigal, \& Rosenbaum, 1990; Taylor, Hack, \& Klein, 1998), without the concurrent hyperactivity that is more typical in psychiatrically diagnosed samples. Here, the unique relation of $\mathrm{pH}$ to attention task performance is consistent with this clinical picture. Although speculative, given the impact on mathematics, attention, and general vocabulary skills, initial $\mathrm{pH}$ likely contributes to the microscopic injury that is hypothesized to occur as a part of prematurity-related damage (Damman \& Leviton, 1999), although it might also create an environment that impairs cell signaling that disturbs general neural development.

Of course, it is possible that $\mathrm{pH}$ is a general marker for more general neural integrity, affecting general cognitive proficiency that happens to be manifest across vocabulary, mathematics, and attention tasks. Three findings speak against this interpretation. First, there was a marginal relation between Apgar score at 1 min and impulsivity, suggesting perhaps that something different-either CNS immaturity or a CNS injury other than hypoxia-ischemia-is related to impulsivity. Second, perinatal $\mathrm{pH}$ was unrelated to performance on tasks that demanded maintaining information in working memory. Working memory often is impaired in samples of children born preterm (e.g., Espy et al., 2002; Luciana et al., 1999), even in those at low risk. If $\mathrm{pH}$ is a generalized marker of neural integrity, $\mathrm{pH}$ would be expected to be related to working memory task performance as well. Surprisingly, Apgar scores at 5 min were inversely related to the Spatial condition of the Six Boxes task (Diamond et al., 1997). That is, children who were more physiologically robust at 5 min post birth required more trials to find all rewards. This counter-intuitive finding might be spurious in this small sample. Interestingly, Diamond, Briand, Fossella, and Gehlbach (2004) have suggested that this task might not adequately capture variations in prefrontal function in this age range. Finally, Apgar scores measured at 1 and 5 min generally were not related to cognitive outcome at 3 years, and if $\mathrm{pH}$ was a marker of general neural integrity, Apgar scores also should robustly predict later cognition.

Although these relations between $\mathrm{pH}$ and cognitive outcome at age 3 years in children born preterm are substantive, it is important to keep in mind that distur- 
bances in $\mathrm{pH}$ can be caused by injuries other than hypoxia-ischemia, for example, metabolic disturbances that arise from kidney malfunction. Although none of the children in this sample were diagnosed with kidney disease, because of the nature of the low risk sample, the specific source of the acid-base disturbance related to cognitive outcome in this exploratory study cannot be determined precisely, as only blood $\mathrm{pH}$ was charted as a screening index for most of these low risk children. Certainly, given the magnitude of the observed relations with several key cognitive domains that often are affected in children born preterm, $\mathrm{pH}$ appears to be an effective marker of later cognitive outcome, even in those without blood acid-base levels are not in the clinically critical range. Furthermore, the sample size of this preliminary is small, enhancing the chance of spurious findings, or minimally that the magnitude of the observed relations will not be as high when a larger, more diverse sample is studied. Certainly, the results from this study, taken together with those by Raz and colleagues (Hopkins-Golightly et al., 2003; Stevens et al., 1999), suggest that perinatal arterial blood $\mathrm{pH}$ warrants further study as a potential marker of subtle hypoxic-ischemic injury that likely affects cognitive outcome throughout childhood in those at risk due to preterm birth.

\section{ACKNOWLEDGMENTS}

This research was supported in part by grants from the Rita Rudel Foundation and the National Institutes of Health, 1R01 DA014661, 1R01 MH065668, and 5P01 HD038051. The authors thank the participating families and staff at Memorial Hospital of Carbondale.

\section{REFERENCES}

Allin, M., Henderson, M., \& Suckling, J. (2004). Effects of very low birth weight on brain structure in adulthood. Developmental Medicine \& Child Neurology, 46, 46-53.

Anderson, P. J., \& Doyle, L. (2004). Executive functioning in school-aged children who were born very preterm or with extremely low birth weight. Pediatrics, 114, 50-57.

Aylward, G. (2005). Neurodevelopmental outcomes of infants born prematurely. Journal of Developmental \& Behavioral Pediatrics, 26, 427-440.

Aziz, K., Vickar, D. B., Sauve, R. S., Etches, P. C., Pain, K. S., \& Robertson, C. M. (1995). Province-based study of neurologic disability of children weighing 500 through 1249 grams at birth in relation to neontal cerebral ultrasound findings. Pediatrics, 95, 837-844.

Breslau, N., Chilcoat, H. \& Johnson, E. (2000). Neurologic soft signs and low birth weight: Their association and neuropsychiatric implications. Biological Psychiatry, 47, 71-79.

Dammann, O., \& Leviton, A. (1999). Brain damage in preterm newborns: Might enhancement of developmentally regulated endogenous protection open a door for prevention? Pediatrics, 104, 541-550. 
Dewey, D., Crawford, S., \& Creighton, D. (1999). Long-term neuropsychological outcomes in very low birthweight children free of sensorineural impairments. Journal of Clinical \& Experimental Neuropsychology, 21, 851-865.

Diamond, A., Briand, L., Fossella, J., \& Gehlbach, L. (2004). Genetic and neurochemical modulation of prefrontal cognitive functions in children. American Journal of Psychiatry, 161, 125-132.

Diamond, A., Prevor, M. B., Callender, G., \& Druin, D. P. (1997). Prefrontal cortex cognitive deficits in children treated early and continuously for PKU. Monographs of the Society for Research in Child Development, 62, 1-205.

DiPietro, J. A., \& Allen, M. C. (1991). Estimation of gestational age: Implications for developmental research. Child Development, 62, 1184-1199.

Eidem, J., \& Espy, K. A. (2005). Neonatal neurobehavioral outcome as a function of maternal smoking and education level. Poster presented at Society for Research in Child Development bi-ennial meeting, Atlanta, GA.

Espy, K. A., McDiarmid, M. D., Cwik, M. F., Senn, T. E., Hamby, A., \& Stalets, M. M. (2004). The contributions of executive functions to emergent mathematic skills in preschool children. Developmental Neuropsychology, 26, 465-486.

Espy, K. A., Senn, T. E., \& Cunningham, D. (2001). Prenatal tobacco exposure: Effects on early neonatal development. Poster presented at the Society for Research in Child Development bi-ennial meeting. Minneapolis.

Espy, K. A., Stalets, M. M., McDiarmid, M. D., Senn, T. E., Cwik, M. F., \& Hamby, A. (2002). Executive functions in preschool children born preterm: Application of cognitive neuroscience paradigms. Child Neuropsychology, 8, 83-92.

Frisk, V., \& Whyte, H. (1994). The long-term consequences of periventricular brain damage on language and verbal memory. Developmental Neuropsychology, 10, 313-333.

Hopkins-Golightly, T., Raz, S., \& Sander, C. (2003). Influence of slight to moderate risk for birth hypoxia on acquisition of cognitive and language function in the preterm infant: A cross-sectional comparison with preterm-birth controls. Neuropsychology, 17, 3-13.

Huppi, P., Warfield, S., \& Kikinis, R. (1998). Quantitative magnetic resonance imaging of brain development in premature and mature newborns. Annals of Neurology, 43, 224-235.

Inder, T., Huppi, P., \& Warfield, S. (1999). Periventricular white matter injury in the premature infant is associated with a reduction in cerebral cortical grey matter volume at term. Annals of Neurology, 46, 755-760.

Isaacs, E. B., Lucas, A., Chong, W. K., Wood, S. J., Johnson, C. L., Marshall, C., et al. (2000). Hippocampal volume and everyday memory in children of very low birth weight. Pediatric Research, 47, 713-720.

Korkman, M., Kirk, U., \& Kemp, S. (1998). NEPSY: A developmental neuropsychological assessment manual. San Antonio, TX: The Psychological Corporation.

Korones, S. B. (1987). Evaluation and management of the infant immediately after birth. In J. Lancaster (Ed.), High-risk newborn infants: The basis of intensive nursing care (2nd ed., pp. 178-189) St. Louis, MO: Mosby.

Lee, M., Vaughn, B. E., \& Kopp, C. B. (1983). Role of self-control in the performance of very young children on a delayed-response memory-for-location. task. Developmental Psychology, 19, 40-44.

Levin, E. D., \& Bowman, R. E. (1986). Long-term lead effects on the Hamilton Search Task and delayed alternation in monkeys. Neurobehavioral Toxicology \& Teratology, 8, 219-224.

Lou, H. C. (1996). Etiology and pathogenesis of attention-deficit hyperactivity disorder (ADHD): Significance of prematurity and perinatal hypoxic-haemodynamic encephalopathy. Acta Paediatrica, $85,1266-1271$.

Luciana, M., Lindeke, L., Georgieff, M., Mills, M., \& Nelson, C. A. (1999). Neurobehavioral evidence for working-memory deficits in school-aged children with histories of prematurity. Developmental Medicine and Child Neurology, 41, 521-533. 
Marin-Padilla, M. (1999). Developmental neuropathology and impact of perinatal brain damage. III: Gray matter lesions of neocortex. Journal of Neuropathology \& Experimental Neurology, 58, 407-429.

Ment, L., Vohr, B., Allan, W., \& Peterson, B. (2003). Change in cognitive functions over time in very-low-birth-weight infants. Journal of the American Medical Association, 289, 705-711.

Peterson, B. S., Anderson, A., \& Ehrenkranz, R. (2003). Regional brain volumes and their later neurodevelopmental correlates in term and preterm infants. Pediatrics, 111, 939-948.

Peterson, B. S., Vohr, B., Staib, L. H., Cannistraci, C. J., Dolberg, A., Schneider, K. C., et al. (2000). Regional brain volume abnormalities and long-term cognitive outcome in preterm infants. Journal of the American Medical Association, 284, 1939-1947.

Petrides, M. (1995). Impairments on nonspatial self-ordered and externally ordered working memory tasks after lesions of the mid-dorsal part of the lateral frontal cortex in the monkey. Journal of Neuroscience, 15, 359-375.

Riccio, C. A., Reynolds, C. R., \& Lowe, P. A. (2001). Clinical applications of continuous performance tests: Measuring attention and impulsive responding in children and adults. New York: John Wiley \& Sons, Inc.

Saigal, S., den Ouden, L., \& Wolke, D. (2003). School age outcomes in children who were extremely low birth weight from four international population-based cohorts. Pediatrics, 112, 943-950.

Saigal, S., Hoult, L., \& Streinder, D. (2000). School difficulties in adolescences in a regional cohort of children who were extremely low birthweight. Pediatrics, 105, 325-331.

Sattler, J. M. (1992). Assessment of children (3rd ed.). San Diego: Jerome M. Sattler Publisher, Inc.

Stevens, C. P., Raz, S., \& Sander, C. J. (1999). Peripatrum hypoxic risk and cognitive outcome: A study of term and preterm birth children at early school age. Neuropsychology, 13, 698-608.

Stevenson, D., \& Sunshine, S. (1997). Fetal and neonatal brain injury: Mechanisms, management, and the risks of practice (2nd ed.). Oxford, England: Oxford University Press.

Szatmari, P., Saigal, S., \& Rosenbaum, P. (1990). Psychiatric disorders at 5 years among children with birthweights less than $1000 \mathrm{~g}$ : A regional perspective. Developmental Medicine \& Child Neurology, 32, 954-962.

Taylor, H. G., \& Alden, J. (1997). Age-related differences in outcomes following childhood brain insults: An introduction and overview. Journal of the International Neuropsychological Society, 3, $555-567$.

Taylor, H. G., Burant, C., \& Holding, P. (2002), Sources of variability in sequelae of very low birth weight children. Child Neuropsychology, 8, 163-178.

Taylor, H. G., Hack, M., \& Klein, N. (1998). Attention deficits in children with $<750$ g. birth weight. Developmental Neuropsychology, 4, 21-34.

Taylor, H. G., Hack, M., Klein, N. K., \& Schatschneider, C. (1995). Achievement in children with birth weights less than $750 \mathrm{~g}$ with normal cognitive abilities: Evidence for specific learning disabilities. Journal of Pediatric Psychology, 20, 703-719.

Taylor, H. G., Klein, N. K., \& Hack, M. (2000). School-age consequences of birth weight less than 750 g: A review and update. Developmental Neuropsychology, 17, 289-321.

Taylor, H. G., Klein, N. K., Minich, N. M., \& Hack, M. (2000). Middle-school-age outcomes in children with very low birthweight. Child Development, 71, 1495-1511.

Volpe, J. J. (1995). Neurology of the newborn (3rd ed.). Philadelphia: W.B. Saunders.

Whitfield, M., Eckstein-Grunau, R., \& Holstik, L. (1997). Extremely premature $(<800$ g) school children: Multiple areas of hidden disability. Archives of Diseases of Childhood, 77, F85-F90.

Woodcock, R. W., \& Johnson, M. B. (1989). Woodcock-Johnson Psycho-Educational Battery-Revised. Allen, TX: DLM Teaching Resources. 